\title{
Economic Development of Small and Medium-Sized Cities in Western China under the Background of Silk Road Economic Belt
}

\author{
LV Ying ${ }^{1, \text { a }}$ \\ ${ }^{1}$ LongDong College, Qingyang City, Gansu Province, 745000, China \\ aemail:
}

Keywords: Silk Road; economic belt; western China; small and medium-sized cities; economic development

\begin{abstract}
The in-depth promotion of the Silk Road economic belt will provide significant development opportunities for the economic development of small and medium-sized cities in western China, which will also be helpful to promote China's westward opening-up strategy, realize regional balanced development, explore new economic growth points, and establish the small and medium-sized city economic system. In this paper, based on the author's learning and practical experience, we firstly analyzed the realistic basis of the promotion of economic development of the small and medium-sized cities in western China via the Silk Road economic belt, and then discussed the great significance of the application of Silk Road economic belt to promote the economic development of small and medium-sized cities in western China. Finally, the strategic measures regarding the promotion of economic development of the small and medium-sized cities in western China via the Silk Road economic belt were put forward.
\end{abstract}

\section{Introduction}

In March 2015, the National Development and Reform Commission, the Ministry of Foreign Affairs and the Ministry of Commerce in China jointly issued the declaration named "vision and action to promote the joint construction of the Silk Road economic belt and the maritime Silk Road in the 21st century", which symbolized that "One Belt and One Road" has entered the pragmatic promotion and concrete construction stages from its concepts and conceptions. Under the background that China's economic operation steps into the new normal and the reform enter the comprehensive deepening stage, and the pressure of economic downturn, it is urgent for China to speed up the construction of the Silk Road economic zone to seek for new economic growth points, build up a new pattern of westward opening-up, and ensure the western strategic security in China[1]. The western China must make full use of the major opportunity of Silk Road economic belt construction to not only achieve their own economic boom and social comprehensive progress, but also help to achieve China's strategic intents.

\section{Realistic Basis of the Promotion of Economic Development of the Small and Medium-Sized Cities in Western China via the Silk Road Economic Belt}

Chinese President Xi Jinping has repeatedly stated in public that the construction of Silk Road economic belt is not a Chinese solo, but the symphony of countries along the belt. However, the symphony requires that the relevant countries and regions have the initial conditions and basis for cooperation. Presently, the countries along the Silk Road economic belt and China's western region already have the conditions and basis for in-depth cooperation, joint construction of the Silk Road, and the realization of the collaborative development.

First, China has increasingly close economic and trade exchanges with the countries along the Silk Road economic belt. In recent years, the regional cooperation between China and Russia, Central Asian countries, South Asia, West Asia and so on continues to deepen. Second, the traffic network between the western China and the Silk Road economic belt has presented the initial profile. The prerequisite of "five links", namely the general requirements of the Silk Road economic belt 
construction previously advocated by President Xi Jinping, is the road connection. After more than twenty-year construction, the transportation capacity of the second Eurasian Continental Bridge has been greatly improved. Third, the cultures of western China and the countries along the Silk Road have the same origins. Historically, several blending processes of culture, religion and nationality have appeared between western China and the countries along the Silk Road. The culture and folk customs in western China characterized by integrity, ruggedness and honesty come down in one continuous line with the countries along the Silk Road. Currently, Xinjiang and Ningxia, the concentrated area of Uygur and Hui communities, have a strong national and religious harmonization with the Central Asian countries. Mongolian and China's Mongol nationality is the same nationality and have the similar folk customs. The Hui and Salar communities in Qinghai have a strong intercommunity with the Central Asian countries in the aspects of religious belief and living habits.

\section{Great Significance of the Promotion of Economic Development of the Small and Medium-Sized Cities in Western China via the Silk Road Economic Belt}

China's "westward opening-up" strategy can be achieved through the construction of Silk Road economic belt. The reform and opening up began in China's southeastern coastal areas, which is admittedly ascribed to the combined action of the objective reasons such as high degree of economic development, more perfect infrastructure and cheaper sea transportation in the eastern market, and the subjective reasons such as the flow of human resources to the eastern areas. However, this phenomenon has resulted in China's opening up presenting a "strong east and weak west, strong sea and weak borderland" pattern[2].

China's regional balanced development can be achieved through the construction of Silk Road economic belt. For a long time, under the guidance of the policy of giving priority to the development in some areas, the eastern region has received the priority in development through the "range-typed" development pattern, while the western region has become the "short board" of coordinated regional economic development in China, which is embodied in many aspects. Taking the per capita GDP level for example, in 2014, only Inner Mongolia ranked in the top ten in the thirty-one provinces of China's mainland, and all the latter ten provinces are from the central and western areas, in which the latter five provinces are from the western areas. The per capita GDP of Tianjin provinces with the highest rank was 226 percent of the national level, while The per capita GDP of Gansu provinces with the lowest rank was only 57 percent of the national level.

China's new economic growth points can be found through the construction of Silk Road economic belt. At present, China's reform has entered the "deep-water areas" and the crucial period. Under the background that the growth dividends in the previous stage have been exhausted, and the increase speed of the economy in northeastern and eastern areas gradually slows down, it is of utmost urgency to seek for and form new economic growth points to maintain 7\% increase amplitude per year of GDP in the new economic normal, and achieve the goal of two "doubles" in 2020.

\section{Strategic Measures of the Promotion of Economic Development of the Small and Medium-Sized Cities in Western China via the Silk Road Economic Belt}

\subsection{Promote the spatial structure adjustment of small and medium-sized cities in western China}

The construction of urban agglomeration and the development of large cities are the main points of the implementation of the Silk Road economic belt in western China. In the construction of the Silk Road economic belt, the western region should develop the cities such as Chongqing, Xi'an, Chengdu, Urumqi and Lanzhou into international metropolis along the Silk Road economic belt, and actively bring the auxiliary drainage action of small and middle-sized cities and towns into full play. The spatial adjustment of small and medium-sized cities and towns can be guided by gradual improvement of the large cities' own ability, which can comprehensively enhance the urbanization level in the western areas. This measure can not only provide the guarantee for the construction of the 
Silk Road economic belt, but also form the city group oriented spatial pattern characterized by the coordinated development of small, middle and large-sized cities and towns.

\subsection{Actively establish economic and trade cooperation relations, and broaden the international market}

Based on the construction of the Silk Road economic belt, a new path has also been developed in the western areas. In the aspects of the economic and trade cooperation, the western areas should constantly adapt to the new development trend of international trade, speed up the adjustment of the structure of foreign trade products, make use of the rich natural resources and unique ecological environment of western provinces, actively and steadily promote the investment through the circular economy, distinctive tourism and modern service industry, combine the multi-ethnic and multi-religious historical and cultural background in partial provinces in the process of enhancing the cultural exchanges with the countries along the Silk Road economic belt, actively explore the regional economic free trade development mechanism, boost the construction of Xi'an inland port, $\mathrm{Xi}$ 'an free trade experimental zone and Kashi economic development zone, promote the development of international trade soft environment, and enhance the new height of the western regional economic development.

\subsection{Accelerate infrastructure optimization and construction, and enhance the regional competitiveness in western China}

The western provinces need speed up the construction of the domestic and international transport corridor with the surrounding countries and regional along the Silk Road economic belt, build a smooth two-way connection transport system, and strengthen infrastructure level of the regional air routes, information networks and energy pipelines in the process of constantly improving the railway and highway transportation construction such as the construction of China-Kyrgyzstan-Uzbekistan highway, China-Pakistan Railway, the Europe-Caucasus-Asia Transport Corridor program of EU, the Pan-European Railway and the China-Tajikistan oil and natural gas pipeline. Besides, the several inside and outside unobstructed channels can be constructed to form the inter-connection three-dimensional integrated transport system and achieve interconnection among countries. In the process of infrastructure construction, advanced investment should be increased, the quality of construction facilities should be consolidated, and the safe operation of economic development carrier should be ensured[3].

\subsection{Improve the industrial development mode, and promote industrial transformation and upgrading}

The western provinces should actively create distinctive industrial system via combining their own advantages, give full play to the advantages of resources and energy, keep a foothold in the actual industrial base, continuously optimize the mode, extend the industrial chain, increase the added value of products, cultivate new economic growth points, and thoroughly accelerate the establishment of the modern industrial system in western provinces. For example, the animal husbandry economy has been fully developed, and animal products resources are rich in the minorities' areas of Xinjiang and Qinghai provinces. Therefore, it is necessary to vigorously develop the textile industry to make the agriculture and textile industries become the pillar industries, which attributes to the establishment of economic structure with local features. The coal resource is rich in Shaanxi, Xinjiang and Ningxia provinces. Therefore, they should actively promote the construction of national large-scale coal production base, "transmission of electricity from the western to the eastern region" project, and national important coal chemical industry base. Xinjiang, Ningxia and Qinghai provinces can speed up the construction of product and industrial concentration areas according to the local circumstances, and create halal food distribution centers in China.

In addition, the establishment of the western regional financial center is also a guarantee for industrial upgrading. Promoting the opening of financial services industry for private capital and improving the enterprises operation environment also have promotion action on the economic development, which can be realized by establishing a sound financial service institutions and setting up industrial investment fund of the Silk Road economic belt[4]. Moreover, they also should continuously improve 
the securities and insurance markets, provide financial services with a wide radiation range and industries, make use of the favorable condition of rich petroleum and clean energy reserves along the Silk Road economic zone, set up a national energy system, and build up a new trading platform.

\subsection{Strengthen social stability construction and promote regional economic security}

The western region is not only one of the backward areas of economic development, but also the typical multi-ethnic concentration areas. Therefore, a series of economic security and social stability challenges appear in the process of economic development[5]. It is necessary to solve some social problems in partial concentration areas such as difficulties in eating, going to school and seeing a doctor, terrorism threat, drugs and AIDS. All the provinces with nationalities concentration areas should formulate corresponding policies and regulations to solve the people's livelihood problems[6]. Furthermore, efforts should be made to improve and enhance the quality of targeted policies, enlarge the executive force of the party and government organizations, enhance government transparency and service awareness, form new cooperative relations, achieve the expectations of the minorities' integration, and strive for the early realization of the beautiful blueprint of harmonious society.

\section{Conclusion}

The Silk Road economic belt has brought not only unprecedented opportunities but also a difficult subject for the development of the western area in China. If this opportunity is missed and nothing is achieved, the economic development of western small and medium-sized cities will lag again. In this paper, based on the analysis of realistic basis and great significance of the economic development promotion of the small and medium-sized cities in western China via the Silk Road economic belt, the detailed development strategic measures were proposed. The rationality of the strategic assumptions need the joint discussion of the academic communities. Their implementation need not only politician's tolerance and share courage, and flexible and pragmatic governance wisdom, but also the joint efforts of the national people in western China and Silk Road economic belt.

Acknowledgements:

Fund project:A scientific research projects of Gansu province's colleges and universities.2016A-090.

\section{References}

[1] GUO Aijun, MAO Jinhuang. Research on the collaborative development between the Silk Road economic belt and the northwest urban agglomerations [J] Gansu Social Science, 2016, (01): 74-79. [2] CHENG Guangbin, SHEN Lijing, LONG Wen. Northwest urban comprehensive capacity comparison under the background of the Silk Road economic belt [J]. Economic Geography, 2015, (08): 98-103+113.

[3] DUAN Xiaomei, HUANG Zhiliang. New opportunities, challenges and tendency of economic development in west China under the background of the new norms [J]. West Forum, 2015, (03): 66-74.

[4] WANG Songji, BAI Yongxiu. Silk Road economic belt construction and western urbanization development and upgrading [J]. Ningxia Social Sciences, 2015, (01): 51-59.

[5] FENG Weijiang. An analysis of international political economy about Silk Road economic belt construction [J] Contemporary Asia-Pacific, 2014, (06): 73-98 + 157-158.

[6] WANG Mingya. Construction of the Silk Road economic belt and its strategic significance [J]. Journal of Tianshui Administration College, 2013, (06): 9-14. 